\title{
DAKWAH BAHASA LOKAL PADA MASYARAKAT KECAMATAN BONTONOMPO SELATAN KABUPATEN GOWA
}

\author{
HERMAN \\ Pascasarjana UIN Alauddin Makassar \\ Email: Hermanjamal1295@gmail.com
}

\begin{abstract}
:
The aim of this reseach is to know the use of Makassar Language in Dakwah activity at South Bontonompo district, Gowa regency. Problem of this research involve: the community understanding about Dakwah through Makassar language at South Bontonompo district Gowa regency; the implementation of in Dakwah through Makassar language at South Bontonompo district Gowa regency. This research used qualitative descriptive research with Normative and Dakwah approach. The researcher get the data from community, Dai, public figure of South Bontonompo district Gowa regency. The method of collecting data are observation, interview, documentation, and literarure review. Data processing and analysis techniques are carried out through three stages namely data reduction, data presentation and conclusion making. The results of this study indicate that: 1) Community understanding of the Makassar language Dakwah in South Bontonompo district of Gowa Regency, namely: a) Da'wah is easier to understand, b) Da'wah is more touching, c) Da'wah is closer (emotional connection), d) Dakwah has meaning deeper; 2) The implementation of the Makassar language in da'wah in South Bontonompo District, Gowa Regency, namely: a). Makassar Sinrili, b). Makassar Kelong, c). Paruntu 'Kana Makassar, d). Pasang Makassar, as well as Khotbah and Lectures.
\end{abstract}

Keywords : Cultural Da'wah, Local Culture, Makassar Language

\section{PENDAHULUAN}

Islam adalah agama dakwah, agama yang menyebarluaskan kebenaran dan mengajak orang-orang yang belum mempercayai untuk percaya, menumbuhkan pengertian dan kesadaran agar umat Islam mampu menjalani hidup sesuai dengan perintah Allah swt. ${ }^{1}$ Nilai-nilai kebenaran dan kebaikan dalam Islam wajib disebarluaskan (dakwah) oleh manusia kepada manusia lain sebab dakwah merupakan tugas suci dan wajib bagi seluruh umat muslim. Dakwah disampaikan sesuai dengan situasi dan kondisi masyarakat yang memiliki budaya lokal tersendiri.

Dakwah sangat berpengaruh terhadap keberhasilan aktivitas manusia dalam berbagai hal dalam mencapai tujuan hidup. Hal ini, dai harus didukung

${ }^{1}$ Faizah dan Lalu Muchsin Effendi, Psikologi Dakwah (Jakarta; Prenamedia Group, 2006), h. 35. 
kemampuan yang baik dalam berkomunikasi. Sehingga menjadi salah satu keberhasilan pertama dalam menjalankan misi suci dakwah sebagai bentuk komunikasi yang khas dalam berdakwah. Dakwah juga memiliki komponen komunikasi yaitu adanya pesan (message), dai (comunicator), ruang, waktu dan tempat (media), serta penerima pesan sebagai sasaran dan objek komunikasi (comunican). ${ }^{2}$ Komunikasi dapat mewujudkan integrasi, dan juga sebaliknya komunikasi bisa menimbulkan desintegrasi apabila dai menyampaikan pesannya kepada mad'u jauh dari kerangka berfikir serta lingkungan dan pengalaman mad'u.

Dakwah kultural menekankan para dai untuk aktif memotivasi sasaran dakwah agar meyakini, memahami, manghayati, dan mengamalkan ajaran Islam melalui pendekatan kebudayaan. Dakwah, komunikasi, dan bahasa adalah trilogi yang satu sama lain saling terkait (interdepedensif). Memang merupakan displin ilmu yang berdiri sendiri, tetapi dalam praktik serta implementasi, ketiganya terpadu sehinggga antara satu dengan yang lain tidak mungkin dipisahkan.

Banyak pesan dakwah yang tidak sampai kepada mad'u karena dai tidak mampu berkomunikasi secara efektif, tidak mampu menuangkan pesannya dalam bahasa yang benar dan baik sesuai situasi/kondisi mad'u. Dakwah yang disajikan kering, gersang, dan hambar. Bahasa yang digunakan membuat mad'u kesulitan memahami pesan dakwah yang disampaikan dai. ${ }^{3}$ Maka dari itu, Pentingnya dai mengedepankan penggunaan bahasa lokal. Bahasa lokal sebagai salah satu unsur kebudayaan yang mencerminkan sebuah peradaban yang tinggi dan masyarakat maju, sebagai sarana menyampaikan informasi yang efektif serta sarana komunikasi yang sopan.

Bangsa yang besar adalah bangsa yang hidup dengan kelenturan budayanya untuk mengaplikasikan unsur-unsur luar yang dianggap baik dan dapat memperkaya nilai-nilai lokal yang dimiliki. Ketidak mampuan beradaptasi budaya luar menempatkan bangsa tersebut dalam kisaran kekerdilan dan kekeringan identitas dan jati diri. Melalui pemakaian bahasa seseorang dapat diketahui kepribadiannya. Seseorang akan sulit diukur kepribadiannya jika mereka tidak mengungkapkan pikiran atau perasaannya melalui tindak bahasa, baik bahasa verbal maupun nonverbal. ${ }^{4}$

Efektifnya sebuah dakwah, harus memperhatikan penggunaan bahasa yang tepat sehingga membuat mad'u terkesima untuk mendengarkan dan

\footnotetext{
${ }^{2}$ H. Toto Tasmara, Komunikasi Dakwah (Cet. 2; Jakarta: Gaya Media Pratama, 1997), h.
} 16.

h. 1 .

${ }^{3}$ Djamalul Abidin, Komunikasi dan Bahasa Dakwah (Jakarta: Gema Insani Press, 1996),

${ }^{4}$ Pranowo. Berbahasa secara Santun (Yogyakarta: Pustaka Pelajar. 2012), h. 3. 
memperhatikan pesan-pesan dakwah yang disampaikan oleh dai. Kebiasaaan berdakwah secara deduktif perlu diimbangi dengan cara befikir dan pendekataan dakwah yang induktif, dakwah keagamaan akan dapat menggunakan bahasa seperti yang dipakai oleh mad'u sehinggah terasa hidup dan aktual. ${ }^{5}$

Sulawesi Selatan dengan beragam etnis/suku di dalamya diantaranya etnis Makassar. Bahasa makassar sebagai media dalam menyampaikan pesan-pesan dakwah memang telah sering digunakan oleh masyarakat di Sulawesi Selatan. Dalam penyebaran ajaran Islam bahasa lokal Makassar digunakan dalam dakwah secara lisan dan juga tulisan. Dalam perkembangannya bahasa Makassar memiliki konstribusi besar terhadap penyebaran ajaran Islam di Sulawesi Selatan. Digunakan dalam penyampaian dakwah secara lisan dan juga secara tulisan yang bisa ditemukan dalam aksara Lontara. ${ }^{6}$

Adanya berbagai nilai-nilai kebudayaan lokal yang relevan dengan nilainilai Islam, harus disampaikan dengan menggunakan bahasa Makassar, agar pesan dakwahnya menjadi lebih kuat dan menyentuh hati. Kerapkali sebagian masyarakat menginginkan nilai-nilai kebudayan lokal sebagai pesan dakwah tidak diakumulasi kebahasa Indonesia. Uraian tersebut, sekaligus tidak menunjukkan bahwa bahasa Indonesia tidak bisa digunakan dai dalam berdakwah, namun bahasa lokal Makassar lebih dan harus sering digunakan dibanding bahasa Indonesia.

Bahasa Makassar sampai pada karya sastra, bahasa kiasan atau syair-syair menjadi cermin dalam budaya masyarakat sebagai bahagian dari aspek paling sempurna yang mencerminkan dan menjelmakan kehidupan dan penghidupan manusia serta masyarakatnya. ${ }^{7}$ Masyarakat etnis makassar yang bertempat tinggal di Kecamatan Bontonompo Selatan Kabupaten Gowa sebagai mahluk budaya melalui akal budinya berupaya melindungi eksistensi dirinya dan budayanya sekaligus, termasuk bahasa Makassar, seperti menggunakan bahasa Makassar dalam aktivitas dakwah.

\section{PEMBAHASAN}

\section{Pemahaman Masyarakat Dengan Dakwah Menggunakan Bahasa Makassar di Kecamatan Bontonompo Selatan Kabupaten Gowa}

Dakwah merupakan suatu bentuk proses menyampaikan ajaran Islam.

${ }^{5}$ Syamsuddin AB, Pengantar Sosiologi Dakwah (Jakarta: Kencana, 2016), h. 236-237.

${ }^{6}$ Mardi Adi Armin, Konstribusi Bahasa Bugis Makassar dalam Penyebaran Mistik Islam di Sulawesi Selatan, Article, https://www.researchgate.net/publication/330010582 (diakses 14 Agustus 2019)

${ }^{7}$ Muh. Ilham, Budaya Lokal Dalam Budaya Makassar Dan Relevansinya Dengan Sarak; Suatu Tinjauan Pemikiran Islam (Makassar: Alauddin University Press, 2013), H. 64. 
Dakwah Islam adalah dakwah ke arah kualitas puncak dari nilai-nilai kemanusiaan dan peradaban manusia. Tentu dengan tujuan utama mewujudkan kesejahteraan dan kebahagiaan hidup di dunia dan di akhirat yang diridhai Allah swt. Yakni dengan menyampaikan nila-nilai Islam yang dapat mendatangkan kesejateraan dan kebahagiaan yang diridhai Allah swt. Sesuai dengan bidang dan keahliannya masing-masing. ${ }^{8}$

Proses penyampaian pesan dakwah dari dai ke mad'u yang berisi mengenai seruan atau ajakan untuk menuju Allah swt. Dai harus mampu mengetahui dan mengerti hal yang dibutuhkan dan disenangi mad'u. Sehingga pesan-pesan dakwah bukan hanya kemauan yang ada dipikiran dari dai namun pesan dakwahnya pula dibutuhkan oleh masyarakat dengan bahasa yang juga bahasa kesaharian mad'u. Hal ini menunjukkan bahwa analisis pesan dakwah dan medan dakwah menjadi sangat penting sehingga pesan dakwah merupakan kebutuhan masyarakat dan sesuai situasi-kondisi mad'u.

Berikut bentuk pemahaman masyarakat dengan dakwah menggunakan Bahasa Makassar di Kecamatan Bontonompo Selatan Kabuapten Gowa sebagai berikut:

\section{Lebih dipahami}

Berdakwah dengan menggunakan bahasa lokal (bahasa setempat mad'u) pada dasarnya akan berperan dalam tingkat pemahaman dan penerimaan pesanpesan dakwah yang disampaikan oleh dai. Agar tujuan dakwah tercapai dengan cepat dan tepat perlu ada cara yang serasi. Dai akan dapat melaksanakan tugas dakwah dengan baik apabila cara dan materinya sesuai dengan situasi dan kondisi objek dakwah (mad'u). Dakwah kerap kali diperhadapkan dengan situasi dan kondisi berlawanan dengan yang prediksi sebelumnya. Namun hal ini mendorong dai agar supaya mempersiapkan materi dan metode yang tepat dan lebih kreatif dalam melatih keahlian dakwah.

Bahasa Makassar telah menjadi sarana komunikasi yang telah melekat erat dalam aktivitas keseharian masyarakat Bontonompo Selatan dan ini pun berlaku pada setiap kegiatan dakwah. Posisi bahasa Makassar dalam menyampaikan materi dakwah yang bertujuan pula memudahkan mad'u memahami maksud materi dakwah sangat sentral. Hal ini dikarenakan bahasa Makassar merupakan bagian dari budaya Makassar yang sejak lama telah digunakan dalam setiap komunikasi baik dalam prosesi tradisi, dakwah dan kegiatan sehari-hari.

Dakwah merupakan aktivitas menyampaikan pesan-pesan Allah SWT. Yang terdapat dalam al-Qur'an dan hadis. Upaya mentransformasikan ajaran-

${ }^{8}$ Muhammad Al-Bahy, Islam Agama Dakwah Bukan Revolusi (Jakarta: Kalam Mulia, 1997), h. 45. 
ajaran Islam kepada masyarakat yang lebih kental dipengaruhi aktivitas oleh budaya/kearifan lokal setempat maka dakwah juga harus menggunkan pendekatan budaya/kearifan lokal setempat (Dakwah Kultural). Begitupun pada masyarakat Bontonompo Selatan yang masih menjaga unsur budaya dalam aktivitas dakwah, dai harus menggunakan pendekatan dakwah kultural yakni salah satunya dengan menggunakan bahasa lokal/daerah Makassar. Hal ini dilakukan untuk mengefektifkan pesan-pesan dakwah yang lebih dapat diterimah dan dipahami dengan baik oleh masyarakat dan secara perlahan meninggalkan hal-hal yang bertentangan dengan Islam dan melakukan yang diperintahkan Allah swt dan RasulNya

Islam dalam penyebaran nilai-nilai kebaikan dan kebenarannya sesuai dengan bahasa masyarakat yang menjadi mad'u. Begitupun al-Qur'an diturunkan tidak semata-mata berbahasa arab, namun Allah SWT, menurunkan al-Quran sesuai dengan lisan arab agar umat Islam mudah memahami dan mengambil pelajaran yang terkandung dalam al-Qur'an. Allah SWT. Berfirman dalam surat ad-Dukhan/44:58:

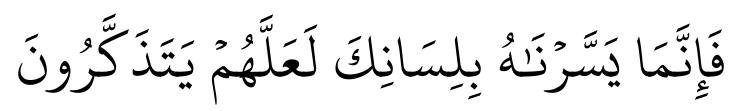

Terjemahnya:

"Sesungguhnya kami mudahkan al-Quran itu dengan bahasamu supaya mereka mendapat pelajaran"9

Berdasarkan ayat di atas, nilai-nilai berupa pelajaran kehidupan kepada seluruh umat sebisa mungkin sesuai dengan bahasa masyarakat setempat. Pesan dakwah oleh seorang dai tidak sekedar disampaikan saja, tetapi mad'u tidak kesulitan memahami pesan dakwah yang berujung pada pengaplikasian pesan dakwah tersebut sehingga tercapai tujuan dakwah itu sendiri. Perlu memperhatikan banyak aspek sehingga yang disampaikan tidak hanya sekedar didengar. Islam dalam penyebarannya dan al-Qur'an sebagai kitabnya disesuaikan dengan bahasa masyarakat dimana al-Qur'an diturunkan supaya al-Qur'an mudah dipelajari dan dipahami yang berdampak pada diterimanya Islam dengan baik.

2. Lebih Menyentuh Hati (Bahasa Hati)

Agama dan budaya lokal yang ada, pada mulanya tumbuh secara isolatif, sekarang mau tidak mau harus berinteraksi dengan yang lain untuk mampu menyelesaikan problem yang makin kompleks. Dakwah sangat menunjang keberhasilan aktivitas manusia dalam berbagai hal untuk mencapai tujuan hidup. Termasuk bagi para dai yang senantiasa memberikan pengajaran, seruan, dan ajakan kepada umat manusia, pada umumnya dan umat Islam pada khususnya,

${ }^{9}$ Kementrian Agama RI, Al-Quran dan Terjemahnya (Jakarta: Samad, 2014), h. 813. 
dengan kemampuan berkomunikasi yang baik merupakan keberhasilan pertama dalam menjalankan misi suci dakwah. ${ }^{10}$

Bahasa Makassar yang digunakan dalam berdakwah harus hati-hati diucapkan juga agar tidak menggunakan bahasa yang dapat menyinggung perasaan atau hati masyarakat Kecamatan Bontonompo Selatan Kabupaten Gowa sebagai mad'u. Bagi masyarakatnya, bahasa Makassar disebut juga bahasa hati, maksudnya yaitu bahasa Makassar sebagai sarana komunikasi juga mengedepankan hati saat saling berkomunikasi sesama masyarakat, begitupun dalam aktivitas dakwah. Ini pertanda bahwa bahasa Makassar bukan sekedar bahasa tradisonal belaka.

Para Ulama dan para Wali dahulunya menggunakan bahasa lokal/daerah yang sesuai dengan bahasa masyarakat setempat sehingga dakwah Islam dapat diterima dengan baik dan jadilah agama yang mayoritas di Indonesia. Bahasa Makassar dalam masyarakat Kecamatan Bontonompo Selatan bukan sekedar bahasa sehari-hari saja namun lebih dari itu. Dalam dakwah pada masyarakat Kecamatan Bontonompo Selatan bahasa Makassar membantu proses dakwah yang efektif begitupun dengan kegiatan kegamaan lainnya.

Setiap wilayah juga mempunyai bahasa daerah masing-masing sebagai sarana komunikasi keagamaan atau digunakan dalam dakwah. Keberagaman bahasa merupakan tanda-tanda kebesaran Allah SWT. Yang dirasakan oleh seluruh umat dalam berkomunikasi atau menyebarkan nilai-nilai Islam. Setiap wilayah dengan bahasa budayanya sendiri tentu secara signifikan berpengaruh dalam komunikasi yang terjadi. Bahasa setiap daerah menjadi sarana menyampaikan pesan-pesan yang sifatnya tradisi/kebudayaan terlebih dalam pesan-pesan ajaran Islam. Budaya yang luhur dalam diri manusia yang berbudaya tentu yang punya relevansi dengan Islam.

Pemahaman mad'u tentang ajaran Islam secara menyeluruh terkait seluruh aspek kehidupan dan mampu mengampilasikannya, walaupun yang paling dasar yakni memahami pesan dakwah dengan baik.

\section{Lebih Dekat (Hubungan Emosional)}

Pada prinsipnya, dakwah Islam diyakini sebagai ajakan dan panggilan dalam berbagai aspek kehidupan umat. Keyakinan seperti ini, harus dibuktikan agar tidak keluar dari nilai-nilai dakwah Islam tersebut. Walaupun disatu sisi perkembangan zaman menghadirkan permasalahan umat yang semakin kompleks maka diperlukan pendekatan dakwah yang tepat dalam merespon problem

${ }^{10}$ H. Toto Tasmara, Komunikasi Dakwah (Cet. 2; Jakarta: Gaya Media Pratama, 1997), h. 16. 
keumatan. $^{11}$

Tindakan dakwah haruslah sesuai kebutuhan mad'u dan dai harus mampu mengontrol aktivitas dakwahnya sehingga antara dai dan mad'u merasa dekat atau bersaudara. Kedekatan itu menjadikan mad'u fokus mendengarkan pesan dakwah dan mudah memahami pesan dakwah yang disampaikan. Budaya lokal Makassar telah menghadirkan hubungan emosioanl antara sesama suku Makassar. Keterikatan emosional sesama orang Makassar, kemudian digeser dalam kegiatan dakwah tentu kegiatan dakwah pun akan terasa lebih dekat (hubungan emosional yang kuat) antara dai dan mad'u.

Materi dakwah disampaikan dengan bahasa Makassar yang sesuai dengan keseharian mad'u di Kecamatan Bontonompo Selatan. Artinya dai akan berada dalam posisi yang lebih dekat secara emosional dengan mad'u. kedekatan ini mengantarkan mad'u untuk hikmat mendengar dan memahami pesan atau materi dakwah. Selanjutnya, dai dianggap menyampaikan materi dakwah dengan tutur kata yang etis (tentu dengan bahasa lokal Makassar yang tergolong sopan), oleh karena sesuai dengan bahasa lokal masyarakat Kecamatan Bontonompo Selatan.

Dari pernyataan di atas bisa dipahami bahwa bahasa Makassar dalam berdakwah menghadirkan hubungan emosional yang kuat atau lebih dekat. Kedekatan secara emosional ini menjadikan pesan dakwah menjadi ingin diperhatikan dan dipahami. Hadirnya keterikatan emosional sesama orang beretnis Makassar di Bontonompo Selatan menjadi hal menguntukkan bagi dai dan mad'u saat dalam proses dakwah. Kesamaan etnis menjadikan sesama masyarakat mudah saling menjaga dan tidak tercerai berai. Islam memerintahkan agar sesama manusia saling melindungi, menjaga dan tidak mendekati perpecahan.

Allah swt. Berfirman dalam Q.S Ali Imran/3:103

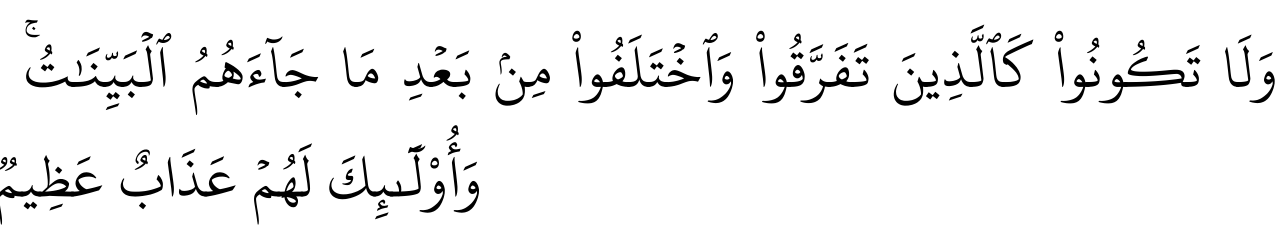

Terjemahnya:

"Dan janganlah kamu menyerupai orang-orang yang bercerai-berai dan berselisih sesudah datang keterangan yang jelas kepada mereka. Mereka itulah orang-orang yang mendapat siksa yang berat"12

Dari ayat di atas menjelaskan bahwa saling menjaga dan saling melindungi satu sama lain tidak bercerai berai atau berselisih. Hal ini bisa terhindar ketika sesama umat manusia saling membangun hubungan emosional yang kuat dan 2004), h.8.

${ }^{11}$ Supiana dan Karman, Materi Pendidikan Agama Islam (Cet. III: Bandung: Rosdakarya,

${ }^{12}$ Kementrian Agama RI, Al-Quran dan Terjemahnya, h. 93. 
kokoh. Menjadikan budaya lokal salah satunya bahasa sebagai upaya selalu menjaga, melindungi dan rukun sesama umat beragama. Setiap dai berharap bahwa setiap pesan dakwah mampu dipahami dengan baik oleh mad'u.

4. Makna Pesan Dakwah Lebih Dalam

Dakwah kultural sebagai suatu konsep dakwah secara konprehensip dengan memahami kecenderungan mad'u (masyarakat) sebagai makhluk berbudaya. Kreatifitas dai dalam mengolah dan mengembangkan aktivitas dakwah diharapkan mampu memperkuat pesan dakwah yang disampaikan. Artinya, dakwah bukan hanya sekedar menyampaikan materi dakwah saja namun perlu diperhatikan bahwa materi dakwah memang diperlukan oleh masyarakat serta disampaikan dengan bahasa yang lebih mudah dipahami, lebih dekat secara emosional, serta mebuat pesan dakwah mempunyai makan lebih dalam sehingga berujung pada pesan dakwah yang betul-betul mengena di pikiran dan hati mad'u.

Harus diperhatikan bahwah dakwah berhadapan dengan masyarakat yang dilingkupi oleh aneka ragam dan budaya. Masyarakat juga terikat dengan adat istiadat dan hukum-hukun tertentu. Sehingga masyarakat memiliki watak dan karakter yang bebeda-beda. Oleh karena itu, dakwah diperlukan pemahaman mengenai konteks sosial dan kondisi mad'u. Memahami kondisi atau mempunyai gambaran awal masyarakat yang menjadi mad'u akan menjadikan pesan dakwah saat pelaksanaan dakwah langsung diterima dengan baik dan bahkan akan kuat tersimpan diingatan mad'u kemudian dilaksanakan.

Dalam mengajak dan menyeruh masyarakat untuk lebih mendekatkan diri kepada Allah SWT. Disampaikan dengan cara yang disenangi dan bahasa keseharian mad'u. Masyarakat Kecamatan Bontonompo Selatan dengan bahasa Makassar sebagai saranan komunikasi, dapat pula digunakan oleh dai dalam berdakwah dengan tujuan membuat pesan dakwah semakin lebih bermakna dan diterimah oleh masyarakat (mad'u).

Dari Penjelasan di atas dapat dipahami bahwa bahasa Makassar menjadikan pesan dakwah menjadi lebih mempunyai makna yang dalam. Dai memang harus berupaya agar pesan dakwah diterima oleh mad'u sekaligus mempunyai makna yang lebih dalam bagi kehidupan masyarakat. Dengan menggunakan bahasa lokal Makassar masyarakat Kecamatan Bontonompo Selatan Kabupaten Gowa sebagai penerima dakwah yang disampaikan oleh dai bisa berupa buah pikiran, keterangan, pernyataan atau sebuah sikap. Artinya makna dari setiap pesan dakwah yang diterima oleh mad'u bisa berbeda namun intinya tentang nilai-nilai keislaman yang kuat dalam pemahaman masyarakat.

Implementasi Bahasa Makassar dalam Dakwah di Kecamatan Bontonompo 


\section{Selatan, Kabupaten Gowa}

Ajaran Islam adalah konsepsi yang sempurna dan konprehensif, karena meliputi segalah aspek kehidupan umat, baik bersifat duniawi mapun ukhrawi. Islam secara teologis, adalah sistem ajaran atau nilai dan ajaran yang bersifat ilahiah dan transenden. Sedangkan dari aspek sosiologis, Islam merupakan fenomena peradaban, kultural, dan realitas sosial dalam kehidupan manusia. ${ }^{13}$

Ajaran Islam disebarkan dengan aktivitas dakwah. Mengimplementasikan bahasa lokal dalam dakwah bisa menjadi sarana tepat dalam memberikan pemahaman ajaran Islam kepada umat yang berbudaya. Begitupun pada masyarakat Kecamatan Bontonompo Selatan Kabupaten Gowa. Bentuk Implementasi bahasa Makassar dalam dakwah meliputi:

\section{Sinrili Makassar}

Sinrili Makassar adalah bentuk kesenian tutur yang sangat populer dikalangan orang Makassar yang dimaksud adalah sebuah cerita yang tersusun rapi dengan bahasa Makassar yang berirama tersusun secara puitis dan biasanya dilagukan oleh ahlinya, yakni seorang pasinrili' (orang yang melakukan sinrili) dan diiringi dengan sebuah instrument gesek yang disebut kesok-kesok atau kerekkerek Gallang. Seorang pasinrili mampu membawakan sebuah ceritera sepanjang malam dengan penuh imajiner, membuat orang-orang terpukau. ${ }^{14}$

Dakwah dengan pendekatan kebudayaan (dakwah kultural) menjadi sebuah pendekatan yang efektif dalam menyampaikan kebenaran dan kebaikan diantara masyarakat yang aktif melestarikan budayanya. Mengimplementasikan bahasa Makassar dalam dakwah salah satunya yakni dengan sinrili. Disampaikan dengan irama bahasa Makassar dengan lirik/kata yang penuh dengan makna kebaikan, mengajak manusia menjaga hubungan dengan sesama, dan menjaga hubungan dengan Allah swt. Memandang dakwah bukanya hanya dengan ceramah, namun lebih laus dakwah bisa dengan metode dan pendekatan yang lain, diantaranya unsur kultur yang relevan dengan Islam dan mengandung Pesan-pesan moral, adab, kebaikan dan kebenaran.

Sinrili dianggap juga sebagai manifestasi berpikir bagi orang Makassar Gowa. Sebagai suatu etnis yang pada masa lampau mempunyai masa kejayaan yang memuncak sehingga mampu menghidupkan nilai-nilai budaya yang tinggi, etika yang kuat hingga sampai hari ini, norma-norma agama yang masih kuat melekat digambarkan lewat alur cerita sinrili yang membuat pendengar

${ }^{13}$ M. Munir. Dan Wahyu Ilaihi, Manajemn Dakwah (Cet. II; Jakarta: Kencana, 2009), h. 1.

${ }^{14}$ M. Sirajuddin Bantang, Sastra Makassar (Makassar, Pustaka Refleksi, 2008), h.1. 
tercengang karena liriknya yang mempunyai makna yang dalam dan pasinrili yang memukau.

Karena bagian dari budaya lokal masyarakat Bontonompo Selatan, disenangi oleh masyarakat, selalu jadi perhatian dan liriknya yang syarat makna nilai-nilai agama Islam. Hal ini bisa menjadi kegiatan yang efektif dalam memberikan pemahaman kepada masyarakat Bontonompo Selatan tentang pentingnya seseorang bermoral, beradab dan tunduk pada Allah swt. Diimplementasikanya bahasa Makassar dalam kegiatan dakwah (dalam arti luas) menghadirkan pesan dan kesan yang berbeda dipikiran dan hati mad'unya.

Penampilan seorang pasinrili, unsur petikan (kobbi), Penuturan yang baik, ekspresi muka yang memukau, dan lirik yang penuh dengan nilai-nilai kebaikan (ajaran Islam). Perkembangan dan perjalan sinrili banyak menceriterakan tentang hubungan manusia dengan tuhan, hubungan manusia dengan manusia, dan bisa menjadi media penyampai informasi kepada masyarakat dan pemerintah. Liriklirik dalam setiap naskah pasinrili selalu mengandung pesan yang baik yang juga kuat keterkaitannya dengan ajaran Islam, tidak ada pertentangan dengan isi alQur'an dan hadis rasul.

Adapun jenis-jenis sinrili terbagi atas tiga yaitu pertama tentang Agama misalnya sinrili Syekh Yusuf al-Mahasin hadiyatullah al-Taj al Khalwati alMakassary Tuanta salamaka. Kedua tentang Perjuangan misalnya Sinrili perang Makassar dan ketiga tentang Cinta Misalnya tentang IJamila Daeng Makanang dengan IBaso Anakodaya. ${ }^{15}$

Lirik-lirik dari sinrili memuat makna yang sangat dalam bagi terwujudnya tatanan kehiduman masyarakat yang selalu menegdepankan adab. Pesan-pesan dakwah yang terdapat dalam lirik-lirik sinrili yang memuat tentang kebijakankebijakan dalam menjalin hubungan sesama manusia dan kebijakan menjalin hubungan manusia dengan Allah swt.

Masyarakat Bontonompo Selatan akan fokus untuk memperhatikan dan menangkap makna atau pesan-pesan kebaikan dalam sinrili. Dengan metode atau pendekatan yang berbeda, bagi masyarakat Kecamatan Bontonompo Selatan pesan-pesan moral-kegamaan dalam sinrili sangat pempengaruhi cara berfikir dan tingkah laku masyarakat.

\section{Kelong Makassar}

Sebagaimana yang kita ketahui bahwa setiap suku bangsa di Indonesia memiliki adat istiadat/budaya yang berbeda, lain suku, lain pula adat istiadatnya.

${ }^{15}$ M. Sirajuddin Bantang, Sastra Makassar h.10. 
Walaupun berbeda-beda namun diikat dalam satu semboyan yakni Bhinneka Tunggal Ika. Semua budaya lokal/adat istiadat adalah milik bangsa Indonesia.

Kelong Makassar yang dibawakan melalui Permainan Kecaping Pasilasila menarik untuk ditonton karena isi kandungan, syairnya yang dibawakan banyak mengandung ajakan keagamaan yang berguna bagi pedoman hidup dimasa yang akan datang. Kelong terdiri dari kelong agama, kelong nasehat, kelong jenaka, kelong paruntu kana dan kelong tebak-tebakan. Permainan kelong Makassar yang dibawakan sangat disukai oleh masyarakat atau pendengar karena mengajak para pendengar pada kebaikan (dakwah) dan ada pula dibawakan dengan jenaka namun memiliki makna yang tinggi. ${ }^{16}$

Contoh kelong agama dalam bahasa Makassar:

\section{Punna mentengko sambayang Pakabaji tajwiknu \\ Salasa kontu \\ Punna rua mukarranu \\ Artinya:}

Kalau mendirikan shalat Perbaiki bacaanmu Kamu akan rugi Jika pikiran bercabang

Sambahyang alle lipa Amala"nu pare baju Iyami antu

Nibokong takle rianja Artinya:

Sembahyang jadikan sarung Amalan jadikan baju

Karena itu

Kekal di hari akhirat

\section{Punna mentengko sambayang Pakabajiki batennu Empo tahiya Nama jarreja junnu'nu Artinya:}

Jika mendirikan shalat Hatilah nan harus baik Memperkuat akan niat

Iyaji kumassambayang Kasambayang kubattui Maka ruanna Singaraknai tubuhku Artinya:

Harus Mendirikan Shalat Sembahyang Wajib Hukumnya Yang Keduanya Untuk Membersihkan Badan

\section{Panraki teyaya toba}

Tu teyaya assambayang

Rugi linona

Sapu ripalak aherakna

Artinya:

Bahaya tidak bertobat

Tidak mau bersembahyang

Rugi dunia

Bangkrut di hari akhirat. ${ }^{17}$

${ }^{16}$ M. Sirajuddin Daeng Bantang, Sastra Makassa,r h.17.

${ }^{17}$ M. Sirajuddin Bantang, Sastra Makassar, h.21-22. 
Banyak nilai-nilai kebaikan yang terkandung dalam kelong Makassar yang pada prinsipnya sejalan dengan nilai-nilai ajaran Islam. Kelong Makassar sebagai sebuah bagian dari kebudayaan Makassar dan termasuk dakwah dalam bingkai nilai-nilai Islam. Karena dakwah bersifat dinamis maka kelong-kelong juga kerapkali dikutip oleh dai disampaikan dalam ceramah dan khutbah.

Dari pernyataan di atas bisa dapahami bahwa masyarakat Kecamatan Bontonompo Selatan memahami kelong sebagai sebuah pesan-pesan kebaikan, kebenaran, moral dan agama yang berguna bagi masyarakat dalam menjalani kehidupan. Rangkaian kata (syair) yang enak didengar dan sangat mengena dihati membuat pendengar hanyut dengan dalamnya makna dari setiap lirik-lirik kelong.

Kegiatan dakwah kultural yang selalu berupaya dalam menanamkan nilainilai keislaman yang mencakup seluruh dimensi kehidupan manusia dengan melihat potensi-potensi manusia sebagai masyarakat budaya sehingga dakwah yang dilakukan mampu diterima oleh masyarakat dengan baik.

\section{Paruntu' Kana Makassar}

Paruntu' Kana termasuk dalam budaya lokal Makassar yang bernilai sastra Makassar yang masih tumbuh dikalangan orang Makassar. Paruntu' kana dapat diartikan sebagai sebuah ungkapan Makassar. Kebudayaan lokal ini umum digunakan oleh masyarakat etnis Makassar untuk menggambarkan kehalusan budi pekerti. Artinya bahwa orang-orang yang mempunyai perasaan dan kehalusan budi pekerti dapat menggunakan kata-kata kias atau paruntu' kana dengan baik. ${ }^{18}$ Berikut beberapa contoh paruntu' kana:

1. Tau tena sobbolo' tolinna (Maksudnya: Orang yang tidak mau mendengar nasehat atau tidak mau dilarang)

2. Tau botto bawa (Maksudnya: Orang yang sering mengeluarkan kata-kata kotor)

3. Sangkammai gunturu bicaranna (Maksudnya: Orang bicara hebat tapi tidak ada buktinya)

4. Amado bukkuru (Maksudnya: Tidak melaksanakan apa yang diakuinya)

5. Tau Assipa' okong (Maksudnya: Orang sabar)

6. Bannang panjaijjaki katte (Maksudnya: Orang yang hanya melaksanakan perintah)

7. Assipa' kaluara (Maksudnya: suka bergotong royong atau kerja sama)

8. Pakammi siring Balla (Maksudnya: Pemalas)

Beberapa contoh paruntu' kana di atas menggambarkan serta menjelaskan sifat dan kondisi seseorang dengan ungkapan atau perumpamaan. Istilah-istilah

${ }^{18}$ M. Sirajuddin Daeng Bantang, Sastra Makassar, h.50. 
dalam paruntu' kana mejadi pesan sekaligus peringatan bagi masyarakat etnis Makassar termasuk masyarakat Kecamatan Bontonompo Selatan. Pesan agar cenderung pada kebaikan dan peringatan untuk tidak mendekati sifat buruk. Oleh karenanya, paruntu' kana menjadi ungkapan-ungkapan masyarakat Makassar yang mempunyai konstribusi meberikan pesan dan peringatan sesuai al-Qura'an dan hadis kepada masyarakat di Kecamatan Bontonompo Selatan Kabupaten Gowa.

Paruntu' kana sebagai salah satu dari keregaman budaya Makassar dengan ungkapan-ungkapan yang berisi peringatan dan pesan kebaikan agar masyarakat bisa berbudi pekerti yang baik. Oleh karena itu, nilai-nilai kebudayaan yang telah melebur dalam diri masyarakat tidak bisa dikatakan semua bahwa bertentangan dengan al-Qur'an dan hadis. Tidak bisa dipungkiri bahwa sebagian dari kebudayaan memang ada yang bertentangan dengan Islam. oleh dasar itu maka dakwah di tengah-tengah masyarakat yang juga menjunjung tinggi nilai-nilai budaya harus dengan pendekatan dakwah kultural untuk bisa memurnikan nilainilai budaya dalam bingkai nilai-nilai Islam.

4. Pa'Pasang Makassar

Pasang yang dapat diartikan dalam bahasa indonesia yakni wasiat, maksudnya pesan orang tua yang berisi petunjuk yang dapat dijadikan kaidah atau pedoman dalam berbagai sektor kehidupan masyarakat, terutama yang berlatar belakang bahasa dan budaya Makassar yang menyangkut berbagai kehidupan misalnya; bidang keagamaan, dan pendidikan moral, bidang sosial, bidang ekonomi, serta kesejahteraan rumah tangga. ${ }^{19}$

Wasiat dengan banyak mengandung ajaran moral ini sangat didukung oleh masyarakat Makassar. Pesan-pesan yang terdapat dalam pasang (wasiat) memberikan pemahaman bagi orang-orang Makassar termasuk di Kecamatan Bontonompo Selatan tentang bagaimana menjalani kehidupan sehari-hari dengan mengedepankan moralitas. Salah satu contoh dapat dikemukakan yang menyangkut pendidikan moral, yakni kejujuran yang harus dimiliki oleh penegak hukum. Berikut contohnya:

Pasanna atiya. Jaga bajiki pandallekanna atinnu, Puna baji' pandallekanna atinnu. Baji' tongi ampe-ampenu rikaraenga siagang parannu nipajjari. Napunna kodi pandallekanna atinnu, Kodi tongi antu pangngampeta ri karaenga siagang riparanta' tunipajari.

Artinya:

Jagalah dengan baik haluan hatimu, Jika hatimu baik, maka baik pula tingkah lakumu pada Allah taala. Jika hati itu tidak baik maka tampaklah

${ }^{19}$ M. Sirajuddin Daeng Bantang, Sastra Makassar, h.52. 
pengaruhnya terhadap Allah taala dan sesama ciptaannya.

Lambusuppi ri karaeng se'reya, malabbusuppi ri paranna karaeng, malambusuki ri pa'rasanganna, malambusukki ri tau jaina, malambusukki ri kalenna, siagang bone balla'na, malambusukki mange risikamma nacinika mata, nalangereka toli.

Artinya:

Jujur kepada Allah swt, jujur kepada sesama raja/pemerintah, jujur kesesama tetangga wilayah, jujur kepada rakyatnya, jujur kepada dirinya sendiri, jujur kepada keluarganya, bahkan jujur kepada segala sesuatu yang baik dilihat maupun yang ghaib. ${ }^{20}$

Dari beberapa contoh pa'pasang yang diuraikan di atas. Kita bisa memahami bahwa pesan-pesan masyarakat Makassar yang berbudaya sejak dulu selalu mengedepankan nilai-nilai kehidupan bernafaskan Islam. Sebagai salah satu kebudayaan sastra etnis Makassar yang juga sangat di senangi oleh masyarakat Kecamatan Bontonompo Selatan, pasang tentunya akan memberikan efek yang sangat positif bagi masyarakat. Wasiat-wasiat ajaran etis dan moral akan memberikan ide yang besar buah pikir yang luhur bagi masyarakat Kecamatan Bontonompo Selatan. Pasang ini bisa menjadi semacam pedoman hidup dalam mengatur tingkah laku dan pergaulan dalam masyarakat.

Hal ini bukan berarti mengeyampingkan al-Qur'an dan hadis sebagi pedoman hidup yang sebenar-benarnya, namun terdapatnya nilai-nilai etis dan moral dalam pasang yang pun relevan dengan al-Qur'an dan hadis. Dalam kegiatan dakwah dimasa sekarang dai di Kecamatan Bontonompo Selatan juga sangat sering mengutip wasiat-wasiat Makassar dalam mempertegas pesan dakwah yang lain.

Keberadaan pasang ditengah-tengah masyarakat berkonstribusi dalam mengetuk pintu hati dan pikiran yang mengarahkan agar umat di Kecamatan Bontonompo Selatan senantiasa berlaku jujur, berfikir dengan akal sehat dan beretika. Dalam menghadirkan tatanan umat yang selalu menjadikan nilai-nilai Islam sebagai pedomannya memang harus diakui tidak mudah, Namun rasa optimisme dalam menghadirkan dan menggunakan pendekatan dan metode dalam berdakwah harus tetap dimiliki. Saling mengingatkan dan memperingati sesama hamba Allah swt merupakan tanggung jawab bersama.

5. Khotbah dan Ceramah

Islam merupakan kumpulan nilai yang diturunkan oleh Allah swt. Kepada Nabi Muhammad saw. Untuk disampaikan kepada seluruh manusia baik hukum aqidah, akhlak, ibadah, dan muamalat serta berita-berita yang disebutkan dalam

${ }^{20}$ M. Sirajuddin Daeng Bantang, Sastra Makassar, h.53-54. 
al-Qur'an dan as-Sunnah. Islam bukan hanya menjelaskann tentang aturan hidup namun juga informasi-informasi atau berita-berita yang diperlukan oleh manusia. $^{21}$

Nilai-nilai yang terkandung dalam al-Qur'an dan as-Sunnah wajib disampaikan atau disebarkan kepada seluruh umat manusia. Banyak metode yang bisa di implementasikan dalam menyebarkan dan menyampaikan nilai-nilai keislaman yang terdapat dalam al-Qur'an dan as-Sunnah seperti khotbah dan ceramah.

Khotbah dan ceramah yakni aktifitas dakwah yang dilakukan oleh dai dengan maksud untuk menyampaikan keterangan, petunjuk, pengertian, dan penjelasan berdasar pada al-Qur'an dan hadis kepada mad'u. Masyarakat kecamatan Bontonompo Selatan, khotbah dan ceramah menjadi aktivitas dakwah yang tentu dilakukan dan terus dilakukan sama seperti di daerah lain. Khotbah seperti khotbah Jum'at, Khotbah idul fitri dan idul adha, ceramah seperti ceramah ramadhan, ceramah taksiah, ceramah jum'at ibadah dan lain-lain.

Namun dalam penyampaian nilai-nilai Islam melalui sebuah ceramah dan khotbah di Kecamatan Bontonompo Selatan Kabupaten Gowa, dai diharapkan dominan menggunakan bahasa Makasar sebagai upaya merespon situasi dan kondisi mad'u. Kondisi dan situasi mad'u dalam aktivitas dakwah di kecamatan Bontonompo Selatan Kabupaten Gowa dalam segi penyampain dakwah dai sebisa mungkin menggunakan bahasa makassar. hal ini dikarenakan adanya kemudahan memahami pesan dakwah yang sampaikan dai ketika dominan menggunakan bahasa Makassar

Mengimplementasikan bahasa Makassar dalam aktivitas dakwah khotbah dan ceramah di Kecamatan Bontonompo Selatan Kabupaten Gowa telah sejak dulu. Artinya telah ada upaya yang telah dilakukan untuk menggunakan bahasa lokal sebagai sarana memperjelas pesan dakwah kepada mad'u. bahasa lokal menjadi sarana yang paling efektif dalam aktivitas dakwah pada masyarakat yang menjunjung tinggi nilai-nilai kearifan lokal seperti masyarakat Kecamatan Bontonompo Selatan Kabupaten Gowa.

Islam sebagai fenomena peradaban, kultural dan realitas sosial dalam kehidupan manusia. Dialektika Islam dengan realitas sosial kehidupan sejatinya merupakan realitas yang terus menerus menyertai agama ini sepanjang sejarahnya. Dalam perkembangannya, Islam tumbuh dan berkembang dalam kondisi yang tidak hampa budaya. Realitas ini harus diakui bahwa memberi pengaruh yang sangat signifikan dalam mengantarkan Islam menuju perkembangan yang aktual dan diakui oleh masyarakat dunia.

${ }^{21}$ Harjani Hefni, Komunikasi Islam (Jakarta: Prenadamedia Group, 2017), h. 10. 


\section{SIMPULAN}

Situasi dan kondisi masyarakat Kecamatan Bontonompo Selatan menjadi pertimbangan dalam melakukan aktivitas dakwah. Salah satunya dengan penggunaan bahasa lokal dalam menyampaikan pesan-pesan Islam sebagai upaya penyesuaian dengan kebutuhan mad'u. Dalam dakwah dengan bahasa Makassar pesan nilai-nilai Islam yang terkandung dalam al-Qur'an dan hadis yang membuat lebih dipahami dan menyetuh hati masyarakat. Memiliki hubungan emosional yang erat, bahasa yang sarat makna, kaya dengan perumpamaan khas orang Makassar yang juga membuat pesan dakwah bisa lebih mudah dimengerti oleh mad'u atau masyarakat.

Berbagai implementasi bahasa Makassar dalam aktivitas dakwah di Kecamatan Bontonompo Selatan juga beragam seperti sinrili Makassar yaitu sarana dakwah yang liriknya berbahasa Makassar dan berisi pesan-pesan moral menjaga hubungan sesama manusia dan hubungan dengan Allah swt. Kelong Makassar yaitu sarana dakwah dalam bahasa Makassar berisi ajakan dalam kegamaan atau peringatan dalam keagaamn. Paruntu' kana Makassar yaitu saranan dakwah dalam bahasa Makassar untuk menggambarkan kehalusan budi pekerti dan peringatan agar bertata krama yang baik. Pasang yakni nasehat atau wasiat dari orang tua terdahalu untuk generasi orang Makassar agar hidup bermoral, beretika, dan berfikir serta bertindak luhur tidak bertentangan dengan nilai-nilai keislaman.

Bahasa dalam bingkai kebudayaan menjadi sarana dakwah yang efektif dalam memberikan pemahaman dan pengajaran kepada masyarakat Bontonompo Selatan Kabupaten Gowa tentang nilai-nilai Islam. masyarakat Bontonompo Salatan memberikan posisi yang tinggi terhadap dakwah berbahasa Makassar karena selain sarana dakwah banyak ungkapan dalam bahasa Makassar yang sarat makna ketika ungkapan-ungkapan berbahasa Makassar di artikan dalam bahasa Indonesia maka maknanya akan jauh berbeda, kurang dipahami dan kurang mengena di hati.

\section{DAFTAR PUSTAKA}

Abidin, Djamalul. Komunikasi dan Bahasa Dakwah. Jakarta: Gema Insani Press, 1996.

Adi, Mardi Armin. Konstribusi Bahasa Bugis Makassar dalam Penyebaran Mistik Islam di Sulawesi Selatan, Article, https://www.researchgate.net/publication/330010582._diakses 14 Agustus 2019). 
Al-Bahy, Muhammad. Islam Agama Dakwah Bukan Revolusi. Jakarta: Kalam Mulia, 1997.

Bantang, M. Sirajuddin. Sastra Makassar. Makassar: Pustaka Refleksi, 2008.

Faizah dan Lalu Muchsin Effendi. Psikologi Dakwah. Jakarta; Prenamedia Group, 2006.

Hefni, Harjani. Komunikasi Islam. Jakarta: Prenadamedia Group, 2017.

Ilham, Muh. Budaya Lokal Dalam Budaya Makassar Dan Relevansinya Dengan Sarak; Suatu Tinjauan Pemikiran Islam. Makassar: Alauddin University Press, 2013.

Kementrian Agama RI, Al-Quran dan Terjemahnya

Munir, M. dan Wahyu Ilaihi. Manajemen Dakwah. Cet. II; Jakarta: Kencana, 2009.

Pranowo. Berbahasa secara Santun. Yogyakarta: Pustaka Pelajar. 2012.

Supiana dan Karman. Materi Pendidikan Agama Islam. Cet. III: Bandung: Rosdakarya, 2004.

Syamsuddin AB. Pengantar Sosiologi Dakwah. Jakarta: Kencana, 2016.

Tasmara, H. Toto. Komunikasi Dakwah. Cet. Ke-2; Jakarta: Gaya Media Pratama, 1997. 